\title{
PARACOCCIDIOIDOMYCOSIS. CLINICAL AND EPIDEMIOLOGICAL STUDIES OF CASES OBSERVED IN THE COURSE OF 25 YEARS, IN MATO GROSSO DO SUL, BRAZIL
}

Thesis: A. M. M. PANIAGO submitted this dissertation for her Doctorate in Tropical Medicine at Oswaldo Cruz Foundation, FIOCRUZ, Rio de Janeiro, Brazil, 2005.

Advisor: Professor Bodo Wanke

Co-advisor: Professor Márcio Neves Bóia

ABSTRACT: Paracoccidioidomycosis (PCM) clinical and epidemiological characteristics, uncommon clinical manifestations and association with AIDS in the state of Mato Grosso do Sul, Brazil, were studied, resulting in five reports of cases observed during 25 years (1980-2004) at the University Hospital of the Federal University of Mato Grosso do Sul (UFMS). We studied the clinical and epidemiological features of 422 PCM cases attended at the University Hospital of the UFMS. Mean age was 43.4 years old and the man:woman proportion was 10:1. The acute/subacute form (15.6\%) presented mainly with lymphadenopathy $(95.4 \%)$ and the chronic form (86.4\%) showed mainly involvement of the lungs (87.3\%) and oropharynx (66.4\%). Sulfamethoxazole/trimethoprim association was used in $90.3 \%$ of the patients. Sequelae were observed in $30.3 \%$ and death occurred in $7.6 \%$ cases. Twelve cases of PCM associated with AIDS were analyzed. The mean age was 36.1 years old and most of the patients had a diagnosis other than PCM as the AIDSdefining illness. Seven patients (58.3\%) showed involvement of more than one extrapulmonary organ. The most often involved organs were: lymph nodes (83.3\%), lung (58.3\%), skin (50\%), and oral mucous membrane (41.6\%). Eight patients died with progressive PCM manifestations. These data reinforce that PCM behaves as an opportunistic disease in AIDS patients. The study of 13 cases of neuroPCM demonstrated that paresis (8/13), headache (5/13), and dizziness (4/13) were the most frequent neurological manifestations. Two patients had exclusive lesions in the central nervous system. The neuroimaging diagnosis showed predominance of multiple and round annular-enhancing lesions after contrast injection. Lesions were seen in brain hemispheres (9/13), thalamus (9/13), cerebellum (4/13), brainstem (4/13), and spinal cord (4/13). The majority of cases presented good therapeutic response with sulfamethoxazole/trimethoprim. The study of 10 patients with osteoarticular PCM showed that the most frequent clinical manifestations were: pain (10/10), tumor (7/10), and redness (6/10) of the compromised region. Radiographs revealed osteolytic lesions in all patients and the majority presented multiple and bilateral lesions. A case of erythema nodosum associated with PCM was diagnosed for the first time.

KEY WORDS: paracoccidioidomycosis, Mato Grosso do Sul, AIDS, central nervous system, bone, erythema nodosum.

\section{CORRESPONDENCE TO:}

ANAMARIA MELLO MIRANDA PANIAGO, Rua das Paineiras, 68 Campo Grande, 79.010-070, MS, Brasil. Phone: 55673383 3691. Email: anapaniago@terra.com.br. 